\title{
Vascularised Sphenoid Mucosal Flap: A Go to Flap in Endoscopic Endonasal Trans-Sphenoidal Pituitary Surgery
}

\section{Rohit Gulati ${ }^{*}$ and Hillol K Pal ${ }^{2}$}

${ }^{1}$ Specialist ENT Surgeon, Thumbay University Hospital, Ajman, UAE

${ }^{2}$ Consultant Neurosurgeon, Thumbay University Hospital, Ajman, UAE

*Corresponding Author: Rohit Gulati, Specialist ENT Surgeon, Thumbay University

Hospital, Ajman, UAE.
Received: May 15, 2020

Published: June 18, 2020

(c) All rights are reserved by Rohit Gulati

and Hillol K Pal.

\section{Abstract}

The endoscopic endonasal trans sphenoidal approach (EEA) is now regarded as the approach of choice for management of a variety of sellar and parasellar pathologies.

Keywords: Sphenoid Mucosal Flap; Endoscopic Endonasal Trans Sphenoidal Approach (EEA)

\section{Introduction}

EEA has many advantages including the fact that it does not require brain retraction and involves minimal neurovascular manipulation.

But sellar reconstruction following EEA does pose a challenge to negate the possibility of post-operative cerebrospinal fluid (C.S.F) leak which can lead to dreaded complications like ascending meningitis or tension pneumocephalus.

Postoperative CSF leak after endoscopic pituitary surgery ranges from 1.9 to 10 percent in different series.

Water-tight reconstruction of the skull defect is thus extremely essential.

\section{Case Reports}

We present two cases where vascularized sphenoid mucosal flaps were used in the reconstruction of the sellar floor defect.

The first case was a pituitary micro-adenoma with a fairly midline inter sphenoid sinus septum.

The inter sinus septal mucosal flaps were raised on both sides in a book like fashion and the inter sinus septum was drilled upto the sella.

After the tumor removal, the sellar defect was reconstructed with a portion of the nasal septal bone and was then draped back again with the sphenoid mucosal flaps on either side.

Fibrin glue was then used to cover the defect and was allowed to polymerise.

No lumbar drainage was done.
The second case was a lot more challenging

The patient presented with CSF Leak following endoscopic endonasal growth hormone macroadenoma resection.

Grade 2 high output CSF leak was identified in the diaphragm sella.

Autologous abdominal fat bath plug was used to plug the hole.

A second layer of temporalis fascia graft extending beyond the edges of the defect was then placed over the fat graft.

A large septal cartilage buttress was then wedged in place (Gasket-Seal Method).

A tongue shaped sphenoid mucosal flap was then harvested from the floor, from one carotid prominence to another over the clivus and draped over the septal cartilage buttress followed by a layer of fibrin glue.

Lumbar drainage was done twice daily for 7 days.

Both cases did very well with no post-operative complications.

\section{Discussion}

Autologous/banked tensor fascia lata, fat and/or muscle has been routinely used for repair of the sella floor defect.

However, in certain instances, the simple use of a Free graft may not be sufficient to withstand the pulsatile force by high pressure of CSF and may lead in post-operative leak or meningitis.

To achieve a more complete closure of the skull base defects, a vascularized flap is deemed more effective. 

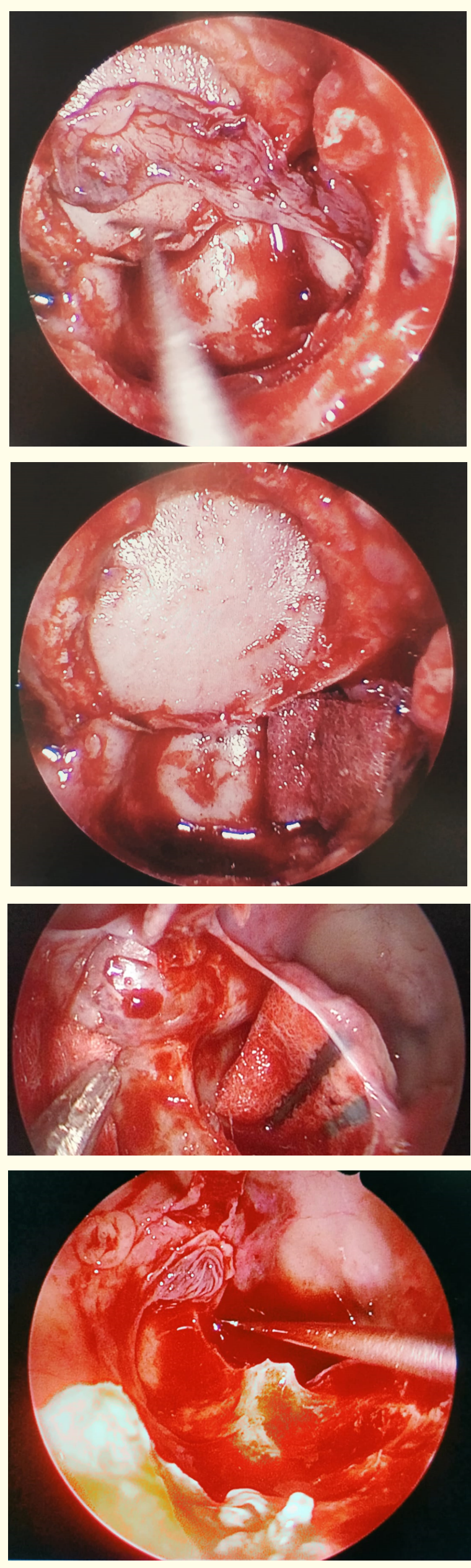
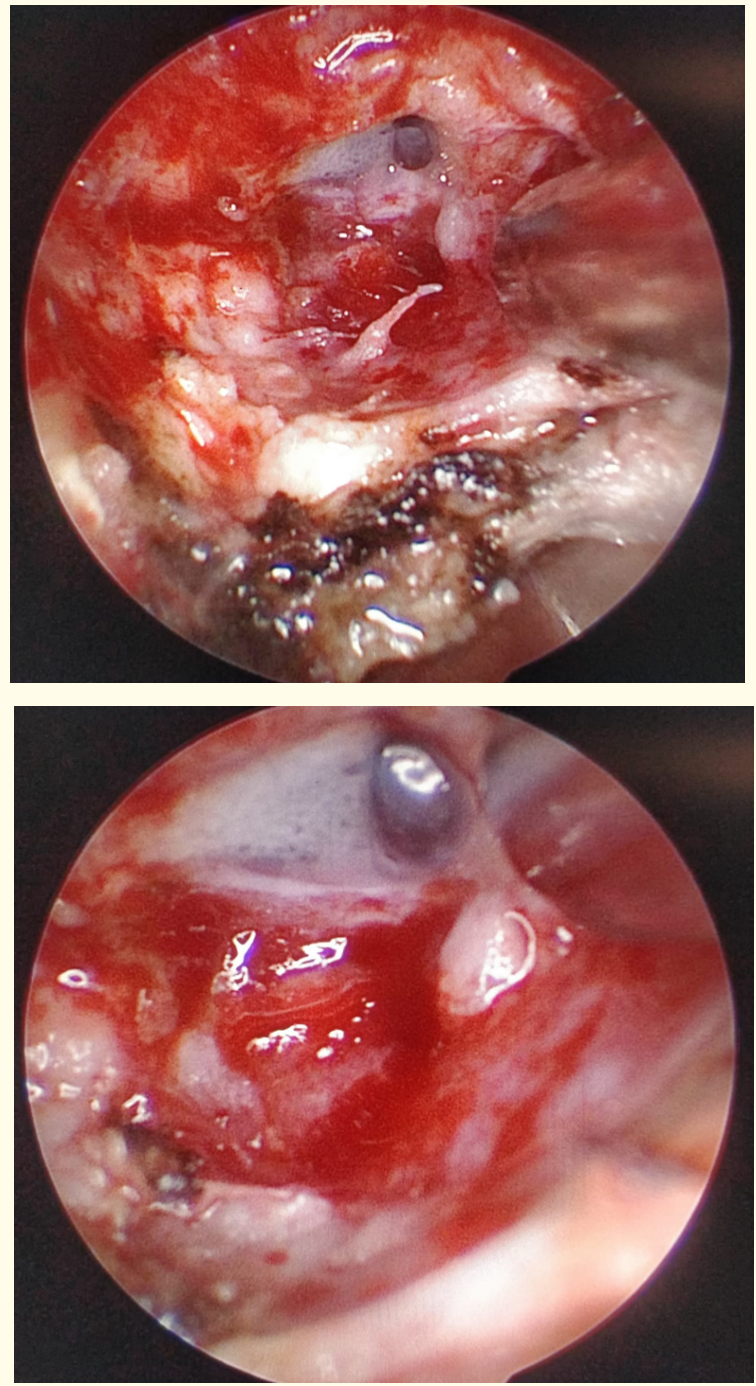

Figures

There is no debate regarding the effectiveness of HADAD- BASSAGASTEGUY Flap which because of its robust pedicled blood supply (Nasoseptal artery), its superior arc of rotation, its modifiable surface area is the go to flap in management of large skull base defects.

But in cases of Small and medium sized sellar defects with low flow or absent CSF leak, vascularized sphenoid mucosal flaps is a very reliable option [1-5].

\section{Conclusion}

Utilization of sphenoid mucosal flaps promoted wound healing and prevented post-operative cerebrospinal fluid leak.

It is fairly reliable and a possibly more acceptable alternative to free grafts in the reconstruction of small and medium sized sellar defects, with or without cerebro-spinal fluid leaks. 


\section{Bibliography}

1. Yoon TM., et al. "Utility of sphenoid mucosal flaps in transnasal transsphenoidal surgery". Acta Oto-Laryngologica 128.7 (2008): 785-789.

2. Goljo E., et al. "Reconstruction of a skull base defect after endoscopic endonasal resection of a pituitary adenoma: Sphenoid mucosal flaps". American Journal of Otolaryngology 39.2 (2018): 253-256.

3. Cappabianca P., et al. "Endoscopic endonasal transsphenoidal approach: outcome analysis of 100 consecutive procedures". Minimal Invasive Neurosurgery 45.4 (2002): 193-200.

4. Laws ER Jr and Thapar K. "Surgical management of pituitary adenomas”. Baillière's Clinical Endocrinology and Metabolism 9.2 (1995): 391-405.

5. Dusick JR., et al. "The extended direct endonasal transsphenoidal approach for nonadenomatous suprasellar tumors". Journal of Neurosurgery 102.5 (2005): 832-841.

\section{Assets from publication with us}

- Prompt Acknowledgement after receiving the article

- Thorough Double blinded peer review

- Rapid Publication

- Issue of Publication Certificate

- High visibility of your Published work

Website: https://www.actascientific.com/

Submit Article: https://www.actascientific.com/submission.php Email us: editor@actascientific.com

Contact us: +919182824667 